\title{
Theoretical Investigations on the $\pi-\pi$ Stacking Interactions in Phenol-Water Complexes
}

\author{
Shruti Sharma, Mrinal J Bezbaruah, Ibrahim Ali, Mahasweta Choudhury, Bipul Bezbaruah* \\ Department of Applied Sciences, Gauhati University, Guwahati, India \\ Email: ^bipulbezbaruah@gmail.com
}

How to cite this paper: Sharma, S., Bezbaruah, M.J., Ali, I., Choudhury, M. and Bezbaruah, B. (2018) Theoretical Investigations on the $\pi-\pi$ Stacking Interactions in Phenol-Water Complexes. Computational Chemistry, 6, 15-25.

https://doi.org/10.4236/cc.2018.62002

Received: April 2, 2018

Accepted: April 27, 2018

Published: April 30, 2018

Copyright () 2018 by authors and Scientific Research Publishing Inc. This work is licensed under the Creative Commons Attribution International License (CC BY 4.0).

http://creativecommons.org/licenses/by/4.0/

\begin{abstract}
Non covalent interactions are quite common in all kinds of $\pi$-systems, such as $\pi-\pi$ interactions, long range/short range van der waal force of interactions, ion- $\pi$ interactions etc. $A b$ initio calculations are well established and account well for the experimental long range interaction energies for small clusters of aromatic molecules and most of the calculations were carried out using the MPn methods. If a reasonably large basis set is used to calculate the stacking interaction energies for a cluster (dimer, trimer etc.) of aromatic molecules then the electron-electron correlation energy may be properly calculated. Moreover, $a b$ initio calculations for aromatic $\pi$-systems show that the calculated stacking interaction energies highly depend on the basis set used and the electron correlation energy. In this investigation, the electron correlation of the stacked hydrated phenol systems has been accounted at MP2 level of calculations. We have calculated the $\pi-\pi$ stacking interaction energies of the hydrated phenolic systems with different conformations.
\end{abstract}

\section{Keywords}

Phenol, $\pi-\pi$ Stacking, MP2, $A b$ initio, etc.

\section{Introduction}

Intermolecular interactions involving aromatic rings are common in many areas of chemistry and biology. In proteins, $\pi-\pi$ stacking has been the subject of systematic search in crystal structures, showing that aromatic side chains preferentially interact in a parallely-displaced orientation [1]. The stacking interaction for different aromatic molecules can also be easily estimated from the extent of the dispersion forces, very short range exchange repulsion forces and electrostatic interactions among the molecules of the system, while the extent of intermolecular electron correlation between aromatic rings is the core factor for cal- 
culating the dispersion forces. However, it is often found that the less accurate force field methods, and even density functional methods have been successfully applied to large molecular systems [2] [3] [4]. The T-shaped structure, shown to arise as well in biomolecules, was found from high level ab initio calculations to be less stable than the parallel arrangement [5]. Moreover, the $a b$ initio calculations with the inclusion of correlation effect at least at the MP2/6-31G* level of theories have been found successfully in some cases. The applications of correlated $a b$ initio methods are limited for small molecules, and the Moller-Plesset perturbation theory (MPn) can be used for medium size molecules [6] [7].

During the last few years, there has been a significant progress in the methods of calculating interaction energies in aromatic complexes. It has been found that stacking stabilization energies computed by MP2 methods with extended basis sets are overestimated especially for stacked structures [8] [9] [10]. Phenol is a simple aromatic system and it can directly interact with each other to form dimer, trimer etc. as similar to water molecules. For sterically hindered phenols and other phenolic systems with bulky groups, it is very difficult to calculate the $\pi-\pi$ stacking interactions accurately. $\pi-\pi$ stacking interactions between hydrated phenol systems have been studied as an initial step to understand the change in hydrogen bonding interactions during pi-pi stacking interaction. Recent studies on phenol-water clusters put more emphasis on the geometries of clusters and the nature of hydrogen bonds [11]-[22]. Dimitrova et al. had investigated the structure and the stability of the hydrogen-bonded complexes of phenol molecule with one to four water molecules by using various levels of $a b$ initio theory and it revealed that for phenol complex with two, three, and four water molecules, the most stable complex was a planar phenol ring [23]. A second-order Møller-Plesset (MP2) perturbation theoretic study using interaction-optimized polarization basis set has revealed the existence of three different minima in the phenol-water complex [24]. Benoit and Clary have studied phenol-water clusters using rigid-body diffusion quantum Monte Carlo method [25] [26]. Earlier studies suggested that the interaction involved in phenol-water clusters is similar in strength to the $\sigma$-hydrogen bond [27]. Ab initio calculations have also been carried out for the electronic ground state and the lowest excited state of phenol and complexes of phenol with water and ammonia and the corresponding cations [28]-[40].

The latter complex is highly interesting as the structure of the dimer is characterized by two different types of non-covalent interactions: The phenol water hydrogen bonding and the stacking of two aromatic rings. The hydrogen bonding is mainly of an electrostatic origin while the aromatic stacking is mainly due to London dispersion interactions, both of which participate in determining the equilibrium structure [41]. Phenol may serve as a basic unit of larger molecules, e.g., tyrosine residues in proteins. The hydrogen-bonded phenol complexes with simple solvent molecules are important models for investigation of $\mathrm{H}$-bonding and proton transfer in proteins and nucleic acids [42]. The study of ionic hy- 
drogen bonded clusters involving phenol and simple molecules, such as water or ammonia, has attracted considerable attention as models for studying numerous biological and chemical processes [43] [44] [45]. In this study, we have investigated the $\pi-\pi$ interactions of hydrated phenol systems with different conformations in gas and aqueous phase.

\section{Computational Methodology}

The most effective method for studying the non-covalent long range interactions of simple aromatic systems is the $a b$ initio method. The study of $\pi-\pi$ stacking interactions has now become much easier due to the quantum mechanical theoretical calculations. The interaction energies for the hydrated phenol systems have been calculated by using Gaussian09 program, using MP2 level of theories and all the hydrated phenol systems have been optimized with the basis set $6-311++G(d, p)$ (Figure 1). These calculations are useful for small clusters of molecules as these explain the binding energies of the smaller molecules in a much effective way. However, the $a b$ initio calculations for studying the $\pi-\pi$ stacking interaction energies highly depend on the electron correlation energy of the molecules and the type of basis set used for calculation. So, the various levels of theories and basis sets have been carefully chosen to calculate the interaction energies of the non-covalent type of interactions and aromatic $\pi-\pi$ stacking, which are primarily responsible for stabilization of different $\pi$-systems.

All the optimized geometries are used for constructing the stacked models of hydrated phenol systems using JoinMolecule package of software. Arguslab/GaussView was also used to visualize and observe the different stacked models. The completely optimized geometries of hydrated phenol systems were taken for calculating the single point energies with MP2/6-311G++(d,p) basis set. Phenol water complexes may directly stack with one another either in eclipsed conformation or staggered conformation. The eclipsed conformation of phenol-water complex shows exact sandwich form at a dihedral angle of $0^{\circ}$. On the other hand, the staggered conformation for phenol-water complex may suitably stacked at different dihedral angles, preferably $60^{\circ}, 120^{\circ}$ and $180^{\circ}$.

The individual models in a stacked conformation are separated at a fixed vertical separation of $3.6 \AA$, as among all the vertical separation ranging from 2.8 to 3.6 $\AA$, between the constructed models, $3.6 \AA$ shows the most favorable conformations of hydrated phenol systems.

Similarly, for all the stacked models, the single point calculations have also been performed. The eclipsed and the staggered forms with different dihedral angles have been taken for constructing various stacked models of hydrated phenol system by shifting one hydrated phenol ring horizontally along the plane of the other. The interaction energies are computed from the following equation:

$$
\text { Interaction energy }=E_{\text {stacked }}-2 E_{\text {single }}
$$

here, $E_{\text {stacked }}=$ Energy of the stacked model and $E_{\text {single }}=$ Energy of the single molecule. All the calculations were carried out with Gaussian 09 program code [45]. 


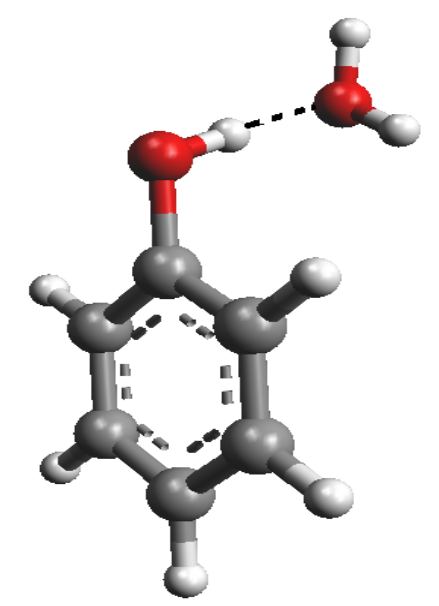

Figure 1. Optimized models of hydrated phenol.

\section{Result and Discussion}

In this research work, the non-covalent $\pi-\pi$ stacking interactions of water assisted phenolic dimers have been studied for different conformations in gas phase and aqueous phase. All the conformations for phenol water stacked systems were prepared with different dihedral angles $-0^{\circ}, 60^{\circ}, 120^{\circ}$ and $180^{\circ}$. The eclipsed conformation, with dihedral angle $0^{\circ}$ was prepared by placing one phenol ring parallely over the other ring with an internal separation of $3.6 \AA$. Then one water assisted phenol ring has been horizontally shifted along either $\mathrm{X}, \mathrm{Y}$ or $\mathrm{Z}$-axis (from positive to negative direction), keeping the other ring at constant position, to get the most favored minimized stacked model. In this case, the horizontal shifting for the stacked model was investigated along $\mathrm{X}$-axis from -3 to +3 $\AA$. Similarly, all the staggered conformations for the stacked models of phenol water systems were also prepared with dihedral angles $60^{\circ}, 120^{\circ}$ and $180^{\circ}$ respectively.

The relative changes for the $\pi-\pi$ stacking interaction energies in gas phase, with MP2 methods for different stacked hydrated phenol conformations are shown in Table 1 and certain stable structures are located from the local minima in the potential energy curves shown in Figure 2 and Figure 3. The intermolecular separation between the stacked models plays an important role in the calculation of effective $\pi-\pi$ stacking interaction energy. The results of MP2 level of theories reflect the extent of dispersion energies accounted in all these calculations. Indeed, the electron correlations included in MP2 level with diffused function in the basis set could estimate more negative stacking energies, where the increase of diffuse function in the basis set provides little change in the energy values.

Among all the stacked models of hydrated phenol systems, it has been observed that the stacking interaction energies of stacked hydrated phenol model with an eclipsed conformation (with dihedral angle $=0^{\circ}$ ) is found to have the most negative value $(-27.4314 \mathrm{kcal} / \mathrm{mol})$ (Table 1$)$. The more negative stacking 
Table 1. Stacking Interaction Energies for minimized stacked models of hydrated phenol systems (Basis set MP2/6-311++G(d,p)).

\begin{tabular}{|c|c|c|c|c|}
\hline \multirow{2}{*}{$\begin{array}{l}\text { Phenol-Water } \\
\text { System }\end{array}$} & \multicolumn{4}{|c|}{$\begin{array}{l}\text { Interaction Energies }(\mathrm{Kcal} / \mathrm{mol}) \text { for Eclipsed and } \\
\text { Staggered conformations }(\text { At } 298 \mathrm{~K})\end{array}$} \\
\hline & $0^{\circ}$ & $60^{\circ}$ & $120^{\circ}$ & $180^{\circ}$ \\
\hline Gas Phase & -27.4314 & -26.4084 & -27.3121 & -26.5610 \\
\hline Aqueous Phase & -24.4211 & -24.4787 & -25.3121 & -24.6658 \\
\hline
\end{tabular}

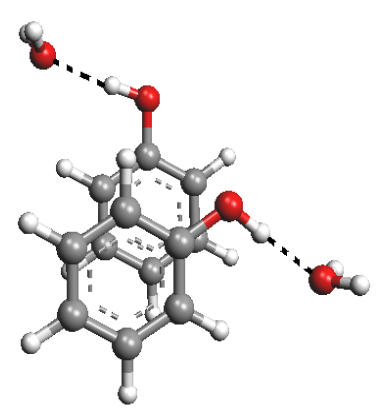

(a)

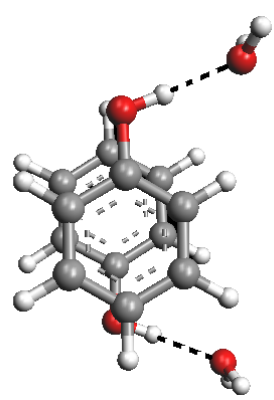

(c)

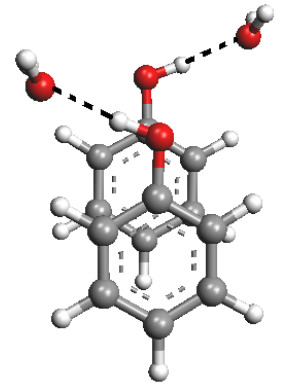

(b)

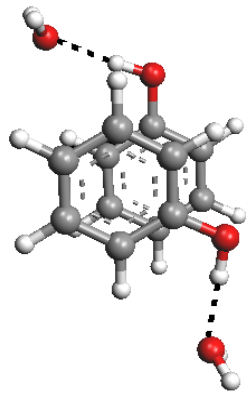

(d)

Figure 2. Minimized stacked models of hydrated phenol systems (a) eclipsed $\left(0^{\circ}\right)$; (b) staggered $\left(60^{\circ}\right)$; (c) staggered $\left(120^{\circ}\right)$ and $(\mathrm{d})$ staggered $\left(180^{\circ}\right)$ conformations.

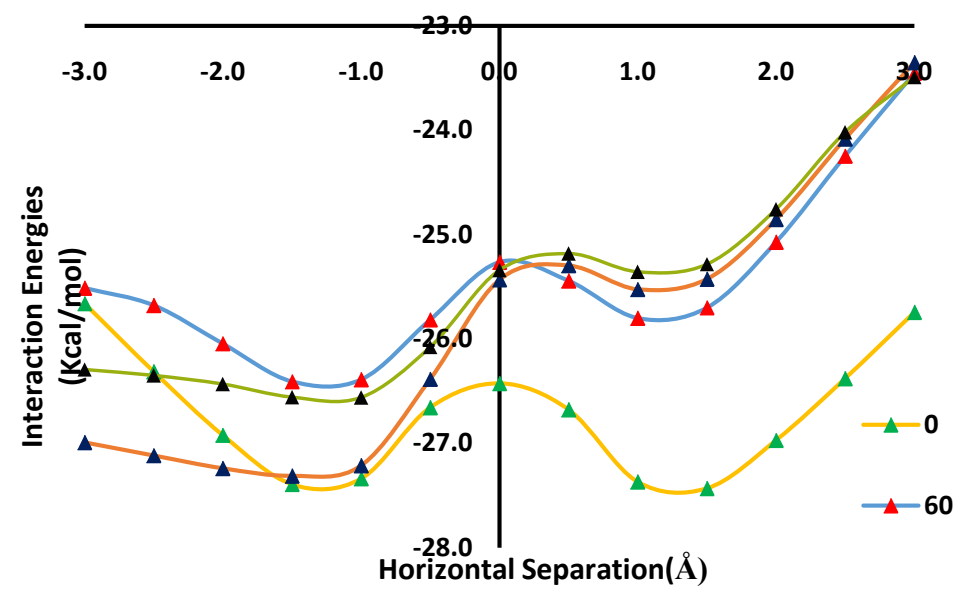

Figure 3. Plot of interaction energies (MP2 single point) versus stacking positions $\left(\mathrm{A}^{\circ}\right)$ for different conformations of hydrated phenol (in gas phase) for the basis set $6-311++G(d, p)$. 
interaction energy values represent the most stable conformation and effective calculation of electron-electron correlation and dispersion forces. On the other hand, the $\pi-\pi$ stacking interaction energy for the staggered conformation with dihedral angle $120^{\circ}$ is found to be $-27.3121 \mathrm{kcal} / \mathrm{mol}$ (Table 1). Figure 2 shows the minimized stacked models for all the hydrated phenol systems with different dihedral angles. The computed stacking energies of optimum structures with various levels of calculations in gas phase are summarized in Table 1.

Above studies for hydrated phenol stacking interactions, show effective $\pi-\pi$ interaction and they are quite well stacked at a dihedral angle of $0^{\circ}$ and $120^{\circ}$. In gas phase at $0^{\circ}$ dihedral angle the minimized energy shows the most negative value $(-27.4314 \mathrm{kcal} / \mathrm{mol})$ at a horizontal shifting of $-1.5 \AA$, it is because of the water molecules of one phenol are far apart from the other which shows minimum electron-electron repulsion, but without any horizontal shifting (at $0 \AA$ ) it show maximum repulsion. On the other hand, at $120^{\circ}$ dihedral angle, the minimized stacked model shows more negative value $(-27.3121 \mathrm{kcal} / \mathrm{mol})$ at a horizontal shifting of $-1.5 \AA$ which represents the minimum repulsion between the phenol water stacked model. However, towards the positive horizontal shifting, the repulsive forces are maximum and therefore they show less negative values. Similar investigations were also done for stacked hydrated phenol systems with dihedral angle of $60^{\circ}$ and $180^{\circ}$. These models shows almost same results and they are less stable as compared to the $0^{\circ}$ and $120^{\circ}$ dihedral angle. We also computed the Mulliken Charges for both gas phase and aqueous phase for minimized stacked models as well as the unstacked phenol system to compare the change in electron charge density of phenol ring. Since, the electron charge density is greatly affected by the $-\mathrm{OH}$ group of the phenol ring both in staked and unstacked models, hence we have investigated the variations of Mulliken charges only for the -OH group (Table 2 and Table 3 ).

It also gives an idea about how effectively it shows the $\pi-\pi$ stacking interaction. Although, we have done our calculations for $\pi-\pi$ stacking interaction both in gas and aqueous phase, but the results reveal that no such major changes have been found in the stability of the stacked models for hydrated phenol as shown in the plots Figure 3 and Figure 4.

Table 2. Mulliken Charges of hydrated phenol systems in gas phase.

\begin{tabular}{|c|c|c|c|c|c|}
\hline \multirow{2}{*}{ System } & \multirow{2}{*}{ Conformation } & \multicolumn{4}{|c|}{ Mulliken Charges } \\
\hline & & Group & Atoms & Unstacked & Stacked \\
\hline \multirow{8}{*}{$\begin{array}{c}\text { HYDRATED } \\
\text { PHENOL }\end{array}$} & \multirow{2}{*}{ Eclipsed $\left(0^{\circ}\right)$} & \multirow{2}{*}{$-\mathrm{OH}$} & $\mathrm{O}$ & -0.3376 & -0.3025 \\
\hline & & & $\mathrm{H}$ & 0.2834 & 0.2939 \\
\hline & \multirow[b]{2}{*}{ Staggered $\left(60^{\circ}\right)$} & \multirow[b]{2}{*}{$-\mathrm{OH}$} & $\mathrm{O}$ & -0.3376 & -0.3025 \\
\hline & & & $\mathrm{H}$ & 0.2834 & 0.2939 \\
\hline & \multirow{2}{*}{ Staggered $\left(120^{\circ}\right)$} & \multirow[b]{2}{*}{$-\mathrm{OH}$} & $\mathrm{O}$ & -0.3376 & -0.3025 \\
\hline & & & $\mathrm{H}$ & 0.2834 & 0.2939 \\
\hline & \multirow{2}{*}{ Staggered $\left(180^{\circ}\right)$} & \multirow{2}{*}{$-\mathrm{OH}$} & $\mathrm{O}$ & -0.3376 & -0.3025 \\
\hline & & & $\mathrm{H}$ & 0.2834 & 0.2939 \\
\hline
\end{tabular}


Table 3. Mulliken Charges of hydrated phenol systems in aqueous phase.

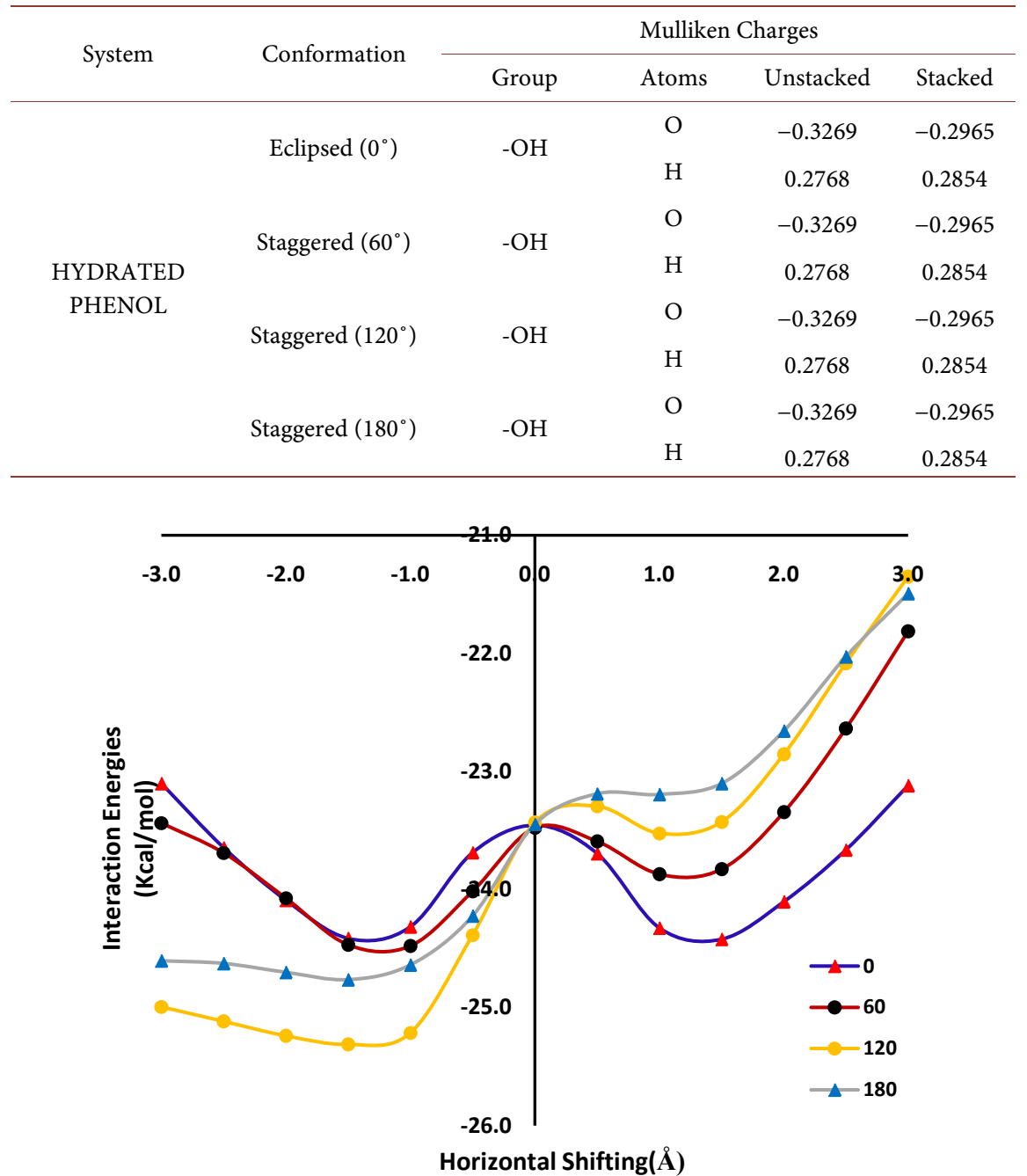

Figure 4. Plot of interaction energies (MP2 single point) versus stacking positions $\left(\mathrm{A}^{\circ}\right)$ for different conformations of hydrated phenol (in aqueous phase) for the basis set $6-311++G(d, p)$.

\section{Conclusion}

Among the different stacked hydrated phenol systems, it has been observed that minimized $\pi-\pi$ stacking interaction energy of the eclipsed conformation (dihedral angle $0^{\circ}$ ) gives more negative interaction energy values as shown in Table 1 and Table 2. It has been observed that most of the phenolic systems give effective $\pi-\pi$ stacking interaction (since all the stacked models give negative stacking interaction energies). Although, some phenolic systems are not always structurally symmetric, but they show effective $\pi-\pi$ stacking between aromatic phenol rings. Therefore, in hydrated phenolic system, eclipsed conformation (dihedral angle $=0^{\circ}$ ) of stacked models show better $\pi-\pi$ stacking interaction than that of other staggered (dihedral angle $60^{\circ}, 120^{\circ}$ and $180^{\circ}$ ) models and it happens due to less repulsive forces. Again, among all the staggered models, stacking models with dihedral angle $120^{\circ}$ shows better $\pi-\pi$ stacking interaction. 


\section{Acknowledgements}

Authors are highly grateful to the AICTE-TEQIP-3, Govt. of India for providing research and financial assistance and the Department of Applied Sciences, Gauhati University, Assam, India.

\section{References}

[1] McGaughey, G.B., Gagne, M. and Rappe, A.K. (1998) $\pi$-Stacking Interactions Alive and Well in Proteins. Journal of Biological Chemistry, 273, 15458. https://doi.org/10.1074/jbc.273.25.15458

[2] Grimme, S. (2003) Improved Second-Order Møller-Plesset Perturbation Theory by Separate Scaling of Parallel- and Antiparallel-Spin Pair Correlation Energies. Journal of Chemical Physics, 118, 9095-9102. https://doi.org/10.1063/1.1569242

[3] Janet, E. and Bene, D. (1988) Ab initio Molecular Orbital Study of the Structures and Energies of Neutral and Charged Bimolecular Complexes of Water with the Hydrides AHn (A = Nitrogen, Oxygen, Fluorine, Phosphorus, Sulfur, and Chlorine). Journal of Physical Chemistry A, 92, 2874-2880.

https://doi.org/10.1021/j100321a035

[4] McDonald, D.Q. and Still, W.C. (1994) Conformational Free Energies from Simulation: Stochastic Dynamics/Monte Carlo Simulations of a Homologous Series of Gellman's Diamides. Journal of the American Chemical Society, 116, 11550-11553. https://doi.org/10.1021/ja00104a039

[5] Hobza, P. and Zahradnik, R. (1988) Intermolecular Inter-Actions between Medium-Sized Systems. Nonempirical and Empirical Calculations of Interaction Energies. Successes and Failures. Chemical Review, 88, 871-897. https://doi.org/10.1021/cr00088a004

[6] Hobza, P., Sponer, J. and Leszczynski, J. (1997) Comment on Electron-Correlated Calculations of Electric Properties of Nucleic Acid Bases. Journal of Physical Chemistry $B, 101,8038-8039$. https://doi.org/10.1021/jp970622f

[7] AlShamaileh, E. (2014) DFT Study of Monochlorinated Pyrene Compounds. Computational Chemistry, 2, 43-49. https://doi.org/10.4236/cc.2014.23006

[8] Wang, D.-F. and Wu, Y.-D. (2004) Density Functional Theory Studies of $\beta$-Substituent Effect on Conformational Preference and Anion Binding Ability of calix[4]pyrroles. Commemorative Issue in Honor of Prof. Chengye Yuan on the Occasion of His 80 th Anniversary, 2004, 96-110.

[9] Sinnokrot, M.O., Sinnokrot, E.F. and Valeev, C.D. (2002) Sherrill, Estimates of the Ab Initio Limit for $\pi-\pi$ Interactions: The Benzene Dimer. Journal of the American Chemical Society, 124, 10887. https://doi.org/10.1021/ja025896h

[10] Sinnokrot, M.O. and Sherill, C.D. (2004) Highly Accurate Coupled Cluster Potential Energy Curves for the Benzene Dimer: Sandwich, T-Shaped, and Parallel-Displaced Configurations. The Journal of Physical Chemistry A, 108, 10200. https://doi.org/10.1021/jp0469517

[11] Jurecka, P. and Hobza, P. (2003) True Stabilization Energies for the Optimal Planar Hydrogen-Bonded and Stacked Structures of Guanine...Cytosine, Adenine...Thymine, and Their 9- and 1-Methyl Derivatives: Complete Basis Set Calculations at the MP2 and CCSD(T) Levels and Comparison with Experiment. Journal of the American Chemical Society, 125, 15608. https://doi.org/10.1021/ja036611j

[12] Ebata, T., Fujii, A. and Mikami, N. (1998) An Infrared Study of $\pi$-Hydrogen Bonds 
in Micro-Solvated Phenol: OH Stretching Vibrations of Phenol-X $\left(\mathrm{X}=\mathrm{C}_{6} \mathrm{H}_{6}, \mathrm{C}_{2} \mathrm{H}_{4}\right.$, and $\mathrm{C}_{2} \mathrm{H}_{2}$ ) Clusters in the Neutral and Cationic Ground States. International Reviews in Physical Chemistry, 17, 331. https://doi.org/10.1080/014423598230081

[13] Feller, D. and Feyereisen, M.W. (1993) Computational Study of Hydrogen Bonding in Phenol-Acetonitrile-Water Clusters. Journal of Computational Chemistry, 14, 1027. https://doi.org/10.1002/jcc.540140904

[14] Watanabe, T., Ebata, T., Fujii, M. and Mikami, N. (1993) Infrared Spectroscopy of $\mathrm{OH}$ Stretching Vibrations of Hydrogen-Bonded tropolone- $\left(\mathrm{H}_{2} \mathrm{O}\right) \mathrm{n}(\mathrm{n}=1-3)$ and tropolone- $\left(\mathrm{CH}_{3} \mathrm{OH}\right) \mathrm{n}(\mathrm{n}=1$ and 2) Clusters. Chemical Physics Letters, 115, 347.

[15] Oikawa, A., Abe, H., Mikami, N. and Ito, M. (1993) Structure and Vibrations of phenol $\left(\mathrm{H}_{2} \mathrm{O}\right)_{2}$. The Journal of Physical Chemistry, 87, 1027.

[16] Gerhards, M. and Kleinermanns, K. (1995) Structure and Vibrations of Phe$\operatorname{nol}\left(\mathrm{H}_{2} \mathrm{O}\right)_{2}$. The Journal of Chemical Physics, 103, 7392-7400. https://doi.org/10.1063/1.470310

[17] Fang, W. and Liu, R.-Z. (2000) Theoretical Characterization of the Structures and Properties of Phenol- $\left(\mathrm{H}_{2} \mathrm{O}\right)_{2}$ Complexes. Journal of Chemical Physics, 113, 5253-5258. https://doi.org/10.1063/1.1290017

[18] Watanabe, T., Ebata, T., Tanabe, S. and Mikami, N. (1996) Picosecond IR-UV Pump-Probe Spectroscopic Study of the Dynamics of the Vibrational Relaxation of Jet-Cooled Phenol. I. Intramolecular Vibrational Energy Redistribution of the $\mathrm{OH}$ and $\mathrm{CH}$ Stretching Vibrations of Bare Phenol. The Journal of Chemical Physics, 105, 408. https://doi.org/10.1063/1.471917

[19] Watanabe, H. and Iwata, I. (1997) A Study on the Structure of Water in an Aqueous Solution by the Solvent Effect on a Volume Phase Transition of $N$-isopropylacrylamide Gel and Low-Frequency Raman Spectroscopy. The Journal of Chemical Physics, 107, 5890. https://doi.org/10.1063/1.474314

[20] Ebata, T., Fujii, A. and Mikami, N. (1996) IR Mass-Resolved Spectroscopy of Complexes without Chromophore: Cyclohexanol. $\left(\mathrm{H}_{2} \mathrm{O}\right) \mathrm{n}, \mathrm{n}=1-3$ and Cyclohexanol Dimer. International Journal of Mass Spectrometry, 159, 111. https://doi.org/10.1016/S0168-1176(96)04445-X

[21] Janzen, Ch., Spangenberg, D., Roth, W. and Kleinermanns, K. (1999) Hydrogen Bonding in Aromatic Alcohol-Water Clusters: A Brief Review. The Journal of Chemical Physics, 110, 9898. https://doi.org/10.1063/1.478863

[22] Jansen, Ch. and Gerhards, M. (2001) Structures and Rearrangement Reactions of 4-aminophenol $(\mathrm{H} 2 \mathrm{O}) 1+$ and 3 -aminophenol $(\mathrm{H} 2 \mathrm{O}) 1+$ clusters. The Journal of Chemical Physics, 115, 5445. https://doi.org/10.1063/1.1394753

[23] Ahn, D.-S., et al. (2003) Hydrogen Bonding in Aromatic Alcohol-Water Clusters: A Brief Review. Bulletin of the Korean Chemical Society, 24, 695-702. https://doi.org/10.5012/bkcs.2003.24.6.695

[24] Dimitrova, Y. (1998) Theoretical Study of Structures and Stabilities of Hydrogen-Bonded Phenol-Water Complexes. Journal of Molecular Structure (Theochem), 455, 9. https://doi.org/10.1016/S0166-1280(98)00237-1

[25] Gibson, Douglas, J. and van Mourik, T. (2001) Stacking with the Unnatural DNA Base 6-ethynylpyridone. Chemical Physics Letters, 668, 7-13. https://doi.org/10.1016/j.cplett.2016.12.009

[26] Benoit, D.M. and Clary, D.C. (2000) Quantum Simulation of Phenol-Water Clusters. The Journal of Physical Chemistry A, 104, 5590-5599.

https://doi.org/10.1021/jp994420q 
[27] Benoit, D.M. and Chavagnac, A.X. and Clary, D.C. (1998) Quaternion Formulation of Diffusion Quantum Monte Carlo for the Rotation of Rigid Molecules in Clusters. Chemical Physics Letters, 283, 269. https://doi.org/10.1016/S0009-2614(97)01396-1

[28] Yi, M. and Scheiner, S. (1996) Proton Transfer in the [phenol-NH3]+system: An Experimental and $A b$ initio Study. Chemical Physics Letters, 262, 567. https://doi.org/10.1016/S0009-2614(96)01135-9

[29] Brutschy, B. (1992) Application of Lanthanide Reagents in Organic Synthesis. Chemical Reviews, 92, 1567. https://doi.org/10.1021/cr00015a005

[30] Dopfer, O., Reiser, G., Muller-Dethlefs, K., Schlag, E.W. and Colson, S.D. (1994) Watching Proton Transfer in Real Time: Ultrafast Photoionization-Induced Proton Transfer in Phenol-Ammonia Complex Cation. The Journal of Chemical Physics, 101, 974. https://doi.org/10.1063/1.467752

[31] Dopfer, O. and Muller-Dethlefs, K. (1994) Noncovalent Interactions: A Challenge for Experiment and Theory. The Journal of Chemical Physics, 101, 8508. https://doi.org/10.1063/1.468111

[32] Suzuki, Y., et al. (1997) A Study on the Structure of Water in an Aqueous Solution by the Solvent Effect on a Volume Phase Transition of N-Isopropylacrylamide Gel and Low-Frequency Raman Spectroscopy. The Journal of Chemical Physics, 107, 5890-5897. https://doi.org/10.1063/1.474314

[33] Lipert, R.J. and Colson, S.D. (1988) Theoretical Characterization of the Excited-State Structures and Properties of Phenol and Its One-Water Complex. The Journal of Chemical Physics, 89, 4579. https://doi.org/10.1063/1.454798

[34] Solgadi, D., Jouvet, C. and Tramer, A. (1988) Picosecond Measurements of Phenol Excited-State Proton Transfer in Clusters. I. Solvent Basicity and Cluster Size Effects. The Journal of Chemical Physics, 92, 3313. https://doi.org/10.1021/j100323a001

[35] Jouvet, C., Lardeux-Dedonder, C., Richard-Viard, M., Solgadi, D. and Tramer, A. (1990) Excited-State Proton Transfer in Gas-Phase Clusters: 2-Naphthol- $\left(\mathrm{NH}_{3}\right) \mathrm{n}$. The Journal of Chemical Physics, 94, 5041. https://doi.org/10.1021/j100375a051

[36] Steadman, J. and Syage, J.A. (1991) C2-symmetric bis(phospholanes) and Their Use in Highly Enantioselective Hydrogenation Reactions. Journal of the American Chemical Society, 113, 6786. https://doi.org/10.1021/ja00018a011

[37] Syage, J.A. and Steadman J. (1992) Photochemistry of phenol- $\left(\mathrm{NH}_{3}\right)$ n Clusters: Solvent Effect on a Radical Cleavage of an $\mathrm{OH}$ Bond in an Electronically Excited State and Intracluster Reactions in the Product $\mathrm{NH}_{4}\left(\mathrm{NH}_{3}\right) \mathrm{n}-1(\mathrm{n}-5)$. The Journal of Chemical Physics, 96, 9606. https://doi.org/10.1021/j100203a009

[38] Mikami, N., Okabe, A. and Suzuki, I. (1988) Photodissociation of the Hydrogen-Bonded [phenol-ammonia]+ heterodimer ion. The Journal of Chemical Physics, 92, 1858. https://doi.org/10.1021/j100318a033

[39] Mikami, N., Sato, S. and Ishigaki, M. (1993) Zero-Kinetic-Energy Photoelectron Spectroscopy of the Hydrogen-Bonded Phenol-Water Complex. Chemical Physics Letters, 202, 431. https://doi.org/10.1016/0009-2614(93)90066-A

[40] Sawamura, T., Fujii, A., Sato, S., Ebata, T. and Mikami, N. (1996) Size Dependence of Intracluster Proton Transfer of Phenol- $\left(\mathrm{H}_{2} \mathrm{O}\right) \mathrm{n}(\mathrm{n}=1-4)$ Cations. The Journal of Chemical Physics, 100, 8131. https://doi.org/10.1021/jp952622q

[41] Parthasarathi, R., Subramanian, V. and Sathyamurthy, N. (2005) Hydrogen Bonding in Phenol, Water, and Phenol-Water Clusters. The Journal of Physical Chemistry $A, 109,843-850$. https://pubs.acs.org/doi/abs/10.1021/jp046499r 
https://doi.org/10.1021/jp953115b

[42] Kolar, M. and Hobza, P. (2007) High-Resolution Rotational Coherence Spectroscopy of the Phenol Dimer. The Journal of Chemical Physics A, 111, 5851-5854.

[43] Michalska, D., Bienko, D.C., Abkowicz-Bienko, A.J. and Latajka, Z. (1996) Density Functional, Hartree-Fock, and MP2 Studies on the Vibrational Spectrum of Phenol. The Journal of Chemical Physics, 100, 17786-17790. https://doi.org/10.1021/jp961376v

[44] Sodupe, M., Oliva, A. and Bertran, J. (1997) Properties of Hydrogen-Bonded Complexes Obtained from the B3LYP Functional with $6-31 G(d, p)$ and $6-31+G(d, p)$ Basis Sets: Comparison with MP2/6-31+G(d,p) Results and Experimental Data. The Journal of Chemical Physics A, 101, 9142-9151. https://doi.org/10.1021/jp970571m

[45] Frisch, M.J., Trucks, G.W., Schlegel, H.B., Gill, P.M.W., Johnson, B.G., Robb, M.A., Cheeseman, J.R., Keith, T., Petersson, G.A., Montgomery, J.A., Raghavachari, K., Al-Laham, M.A., Zakrzewaki, V.G., Ortiz, J.V., Foresmann, J.B., Ciolowski, J., Stefanov, B.B., Namayakkara, A., Challacombe, M., Peng, C.Y., Ayala, P.Y., Chen, W., Wong, M.W., Andres, J.L., Replogle, E.S., Gomperts, R., Martin, R.L., Fox, D.J., Binkley, J.S., Defrees, D.J., Baker, J., Stewart, J.P., Head-Gordon, M., Gonzalez, C. and Pople, J.A. (2009) Gaussian 09. Gaussian Inc., Pittsburgh. 